\title{
Central Diabetes Insipidus Associated with a Missense Mutation in the Arginine Vasopressin Gene that Replaces Ala at the Carboxyterminus of the Signal Peptide with Thr
}

\author{
Akiko Kawakami, Yasuyuki Окамото*, Tsunehiko Yамамото, Youichi Tatsumi, \\ Takami MIKI**, Shiro TANAKA and Satoru FUJII
}

\begin{abstract}
We report an 18-year-old male with a history of polyuria, polydipsia, and thirst since childhood. In a hypertonic saline infusion test, the patient's plasma vasopressin rose only to 0.28 $\mathrm{pg} / \mathrm{ml}$. In a water deprivation test, his urinary osmolality rose only to $189 \mathrm{mosmol} / \mathrm{kg}$ and then rose to $538 \mathrm{mosmol} / \mathrm{kg}$ by vasopressin administration. A T1-weighted magnetic resonance imaging (MRI) scan revealed a loss of the posterior pituitary bright spot. Sequencing of the vasopressin gene showed a heterozygous point mutation that replaced Ala at the carboxyterminus of the signal peptide with Thr. His father also had similar history, and we therefore diagnosed his illness as familial central diabetes insipidus.
\end{abstract}

(Internal Medicine 37: 683-686, 1998)

Key words: autosomal dominant, polyuria, polydipsia, posterior pituitary

\section{Introduction}

Familial central diabetes insipidus (FCDI) is a disorder of renal water conservation due to an inherited deficiency of the peptide hormone arginine vasopressin (AVP). Affected individuals are normal at birth but become symptomatic with polyuria and polydipsia typically at $1-6$ year of age due to progressive AVP deficiency (1).

Affected members of FCDI families have been found to be heterozygous for mutations in the AVP gene. The AVP gene is located on human chromosome 20 and consists of 3 exons (2). Exon 1 encodes the signal peptide, AVP, and the aminoterminal region of neurophysin II (NPII). Exon 2 accounts for the central region of NP II, and exon 3 contains the carboxyterminal region of NP II and glycoprotein (3). Four different FCDI mutations have been described that encode changes in the signal peptide (4-8). One missense mutation within the vasopressin-coding sequence (9) and 12 missense mutations, 1 deletion, and 5 nonsense mutations within the coding sequence of NP II $(7,10$ 15), have also been described as causing FCDI.

Here, we report an 18-year-old patient with central diabetes insipidus (CDI) diagnosed by chance during the treatment of iron-deficiency anemia.

\section{Case Report}

The index case is an 18-year-old male who was referred to our hospital for the treatment of iron-deficiency anemia due to low iron intake. It was learned in taking a detailed history that the patient had a history of polyuria, polydipsia, and thirst since childhood. Upon initial examination, the basal urine osmolality was $253 \mathrm{mosmol} / \mathrm{kg}$. In a $5 \%$ hypertonic saline infusion test, his serum osmolality rose from 297 to $308 \mathrm{mosmol} / \mathrm{kg}$, but his plasma AVP rose only to $0.28 \mathrm{pg} / \mathrm{ml}$. In a water deprivation test (Fig. 1), his peak plasma osmolality rose to $299 \mathrm{mosmol} / \mathrm{kg}$, but his urinary osmolality rose only to $189 \mathrm{mosmol} / \mathrm{kg}$. When exogenous vasopressin was administered, his urine osmolality rose to $538 \mathrm{mosmol} / \mathrm{kg}$. A T1-weighted magnetic resonance imaging (MRI) scan of his brain revealed a loss of the posterior pituitary bright spot (Fig. 2). Based upon these test results, we diagnosed his illness as CDI. We suspected him to be a patient with FCDI because his father also had a history of polyuria, polydipsia, and thirst since his childhood. However, we could not make contact with the father to study his AVP secretion

From the Department of Internal Medicine, Osaka City General Hospital and **the Department of Geriatric Medicine and Neurology, Osaka City University, Osaka, *present address: Sumire Hospital, Osaka Social Welfare Foundation, Osaka 


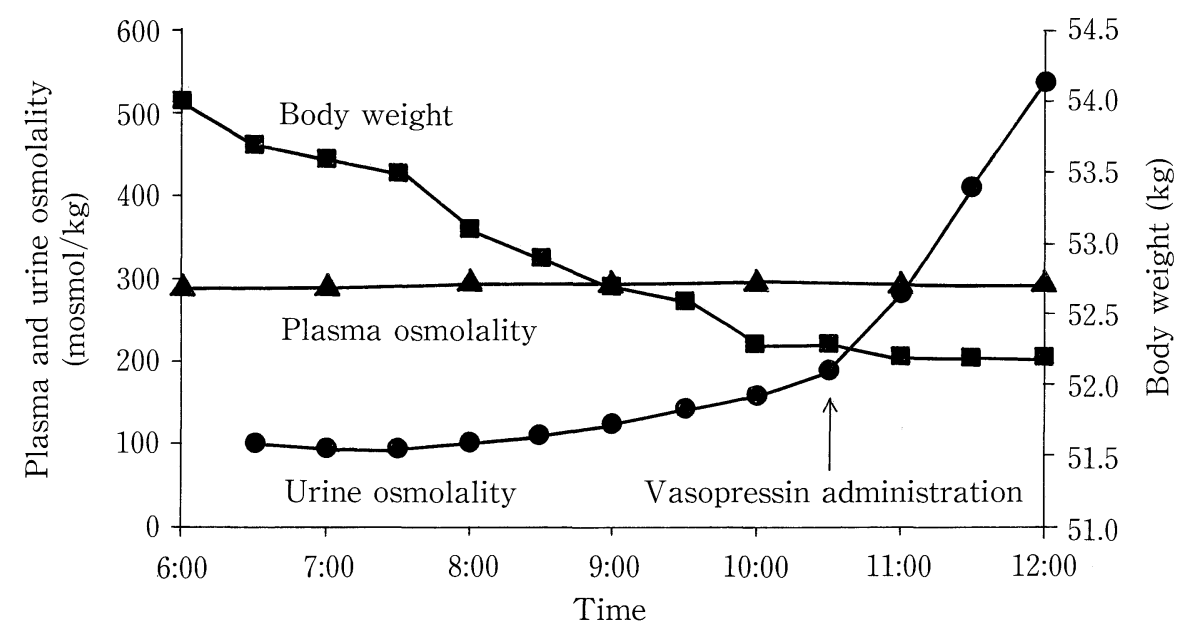

Figure 1. Water deprivation test. The patient emptied his bladder at 6:00 AM and was then weighed. An intravenous cannula was inserted, and no water was allowed until 10:30 AM, when more than $3 \%$ of the initial body weight was lost. A $10 \mathrm{U}$ dose of vasopressin was given intramuscularly at 10:30 AM (arrow). Urine volume, osmolality of plasma and urine, and body weight were recorded as shown.

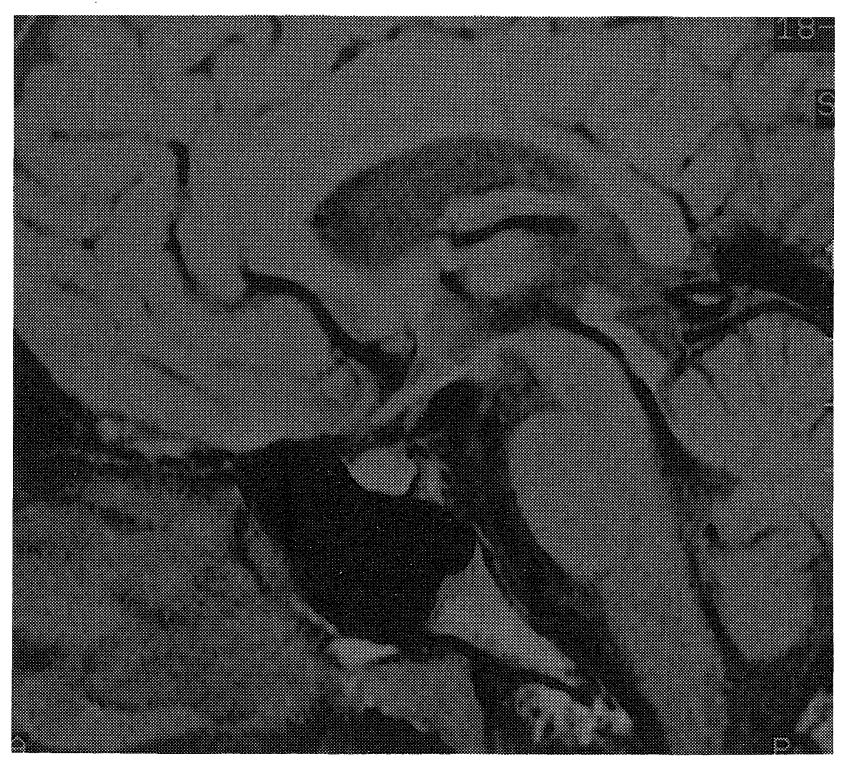

Figure 2. MRI sagittal scan of the hypothalamus and pituitary of the patient. A T1-weighted image showed a loss of the posterior pituitary bright spot.

because the patient's parents were divorced. We also could not obtain any information on his father's family. To confirm that the patient had a genetic abnormality in the AVP gene, we studied the mutation present in the AVP gene for both him and his family. The institutional review board approved this study, and informed consent was obtained from the subjects.

Genomic DNA was isolated from peripheral blood leukocytes. Each of the three exons of the AVP gene was amplified by polymerase chain reaction (PCR). The nucleotide sequence of the PCR products was determined directly by thermocycle sequencing as previously described (7). Sequencing of exon 1 showed a G-to-A point mutation at base 279 , and the patient was heterozygous for the mutation (Fig. 3). This mutation replaces Ala (GCG) at the carboxyterminus of the signal peptide ( -1 pisition) with Thr (ACG). The patient's mother and sister did not have any mutation in exons 1 to 3 of the AVP gene. To confirm the presence of this point mutation, a restriction endonuclease digestion of PCR-amplified exon 1 was performed. This mutation introduced a restriction site for PmaC I (CGCGTG $\rightarrow$ CACGTG). A 275-bp exon 1 that included the mutation site was amplified by PCR, using the same primer for the sequencing, and was subjected to digestion by PmaC I. As predicted, agarose gel electrophoresis of PmaC I-digested patient's exon 1 revealed an undigested 275-bp band from the normal allele and 174- and 101-bp digested bands from the mutant allele (Fig. 4). In contrast, his mother and his sister showed only a normal 275-bp band, indicating they were normal.

\section{Discussion}

We identified the G-to-A point mutation at base 279 in exon 1 of the AVP gene in the patient with CDI. His father had also had a history of polyuria, polydipsia, and thirst since his childhood. Although we could not evaluate the AVP secretion in the patient's father, we highly suspected this to be a case of a patient with FCDI. Thus far, 24 different mutations in the AVP gene have been identified in 31 unrelated kindreds (16), including unpublished reports. The G-to-A point mutation at base 279 in exon 1 is the most frequent of these mutations, and five unrelated kindreds, including one Japanese family, with the mutation have been reported $(4,5,7)$. Although varied in 


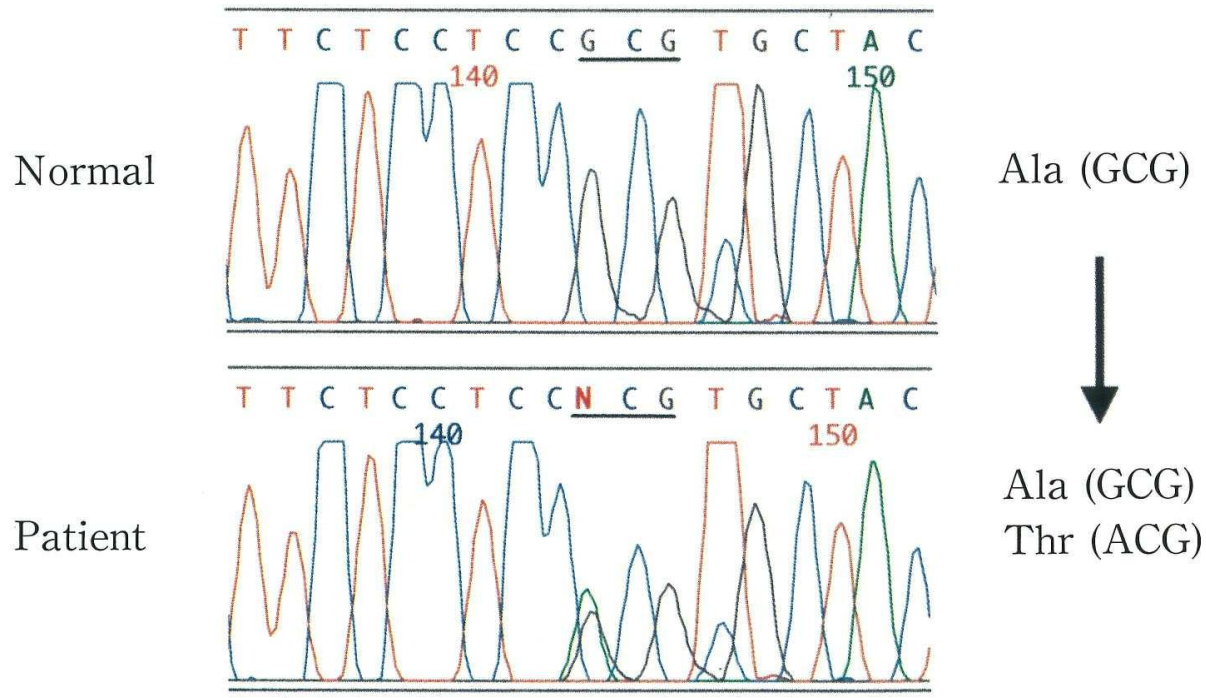

Figure 3. Heterozygous AVP gene mutation detected by DNA sequencing. The amplified exon 1 of the AVP gene from the patient and his sister (normal) were directly cyclesequenced with the dideoxy chain-termination method and applied to an autosequencer (ABI prism 310 DNA sequencer, Applied Biosystems). Two fluorescence peaks were found on the lower panel at base 279 (shown as " $\mathrm{N}$ "), demonstrating a heterozygous G-to-A transversion (Ala $\rightarrow$ Thr).

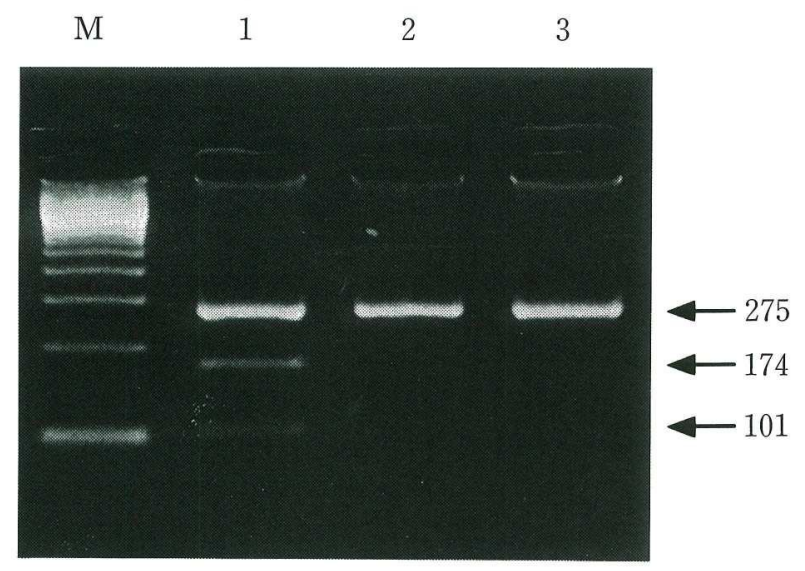

Figure 4. Restriction analysis of exon 1 of the AVP gene of the proband and other family members. The mutation introduces a new restriction site for PmaC I. The restriction digests from the patient (1) yielded 101-, 174-, and intact 275-bp fragments, whereas those from the patient's sister (2) and his mother (3) yielded only 275-bp fragments. $M=100$-bp ladder (GIBCO).

location and nature, these different mutations appear to result in a similar phenotype. The only difference observed thus far is that the mutation in the present case appears to be associated with a slightly later onset of the disease ( 3 to 6 years of age) than those that replace the glycine at base 1859 ( 0.5 to 1.5 years of age) (16). In our case, neither the patient nor his family recognized his polyuria and polydipsia as symptoms of CDI.
Therefore, he was left for a long period without treatment. The patient is now successfully treated with desmopressin, and his quality of life has greatly improved. In contrast to nephrogenic diabetes insipidus, which is associated with severe symptoms and complications of diabetes insipidus from birth, FCDI typically first produces symptoms of vasopressin deficiency at 1-6 years of age. This gradual loss of function may make patients and their families unaware of symptoms of FCDI.

It has been postulated that in FCDI the dominant inheritance results from a progressive neurological degeneration of the hypothalamic magnocellular neurons that produce circulating AVP (17). The signal peptide mutation of AVP results in an abnormally processed precursor protein in vitro (5). Ito and Jameson have recently reported that mutant AVP precursors, including our patient's mutation, induce neuronal cell death as a result of their accumulation within the endoplasmic reticulum, suggesting that the pathogenesis of FCDI may be caused by the cytotoxicity of mutant precursor proteins (18).

We reported herein a case of CDI caused by a mutation of the AVP gene exon 1. Although there is no denying that the patient's mutation in the AVP gene was somatic, we highly suspect him to be a patient with FCDI.

Acknowledgements: We wish to thank Aya Kaibara for her technical assistance. This work was supported by a grant from the Osaka City General Hospital for medical research.

\section{References}

1) Kaplowiz PB, D'Ercole AJ, Robertson GL. Radioimmunoassay of vasopressin in familial central diabetes insipidus. J Pediatr 100: 76, 1982. 


\section{KAWAKAMI et al}

2) Riddell DC, Mallonee R, Phillips JA, Parks JS, Sexton LA, Hamerton JL. Chromosomal assignment of human sequences encoding arginine vasopressin-neurophysin II and growth hormone releasing factor. Somatic Cell Mol Genet 11: 189, 1985.

3) Sausville E, Carney D, Battey J. The human vasopressin gene is linked to the oxytocin gene and is selectively expressed in a cultured lung cancer cell line. J Biol Chem 260: 10236, 1985.

4) McLeod JF, Kovacs L, Gaskill MB, Rittig S, Bradley GS, Robertson GL. Familial neurohypophyseal diabetes insipidus associated with a signal peptide mutation. J Clin Endocrinol Metab 77: 599A, 1993.

5) Ito M, Oiso $Y$, Murase $T$, et al. Possible involvement of inefficient cleavage of preprovasopressin by signal peptidase as a cause for familial central diabetes insipidus. J Clin Invest 91: 2565, 1993.

6) Krishnamani MRS, Phillips JA III, Copeland KC. Detection of a novel arginine vasopressin defect by dideoxy fingerprinting. J Clin Endocrinol Metab 77: 596, 1993.

7) Rittig S, Robertson GL, Siggaard C, et al. Identification of 13 new mutations in the vasopressin-neurophysin II gene in 17 kindreds with familial autosomal dominant neurohypophyseal diabetes insipidus. Am J Hum Genet 58: 107, 1996.

8) Rutishauser J, Boni-Schnetzler M, Boni J, et al. A novel point mutation in the translation initiation codon of the pre-pro-vasopressin-neurophysin II gene: cosegregation with morphological abnormalities and clinical symptoms in autosomal dominant neurohypophyseal diabetes insipidus. J Clin Endocrinol Metab 81: 192, 1996.

9) Rittig S, Siggaard C, Ozata M, et al. Familial neurohypophyseal diabetes insipidus due to mutation that substitutes histidine for tyrosine 2 in the antidiuretic hormone [abst]. J Invest Med 44: 387A, 1996.

10) Ito M, Mori $Y$, Oiso $Y$, Saito H. A single base substitution in the coding region for neurophysin II associated with familial central diabetes insipidus. J Clin Invest 87: 725, 1991.

11) Bahnsen U, Oosting P, Swaab DF, Nahke P, Richter D, Schmale H. A missense mutation in the vasopressin-neurophysin precursor gene cosegregates with human autosomal dominant neurohypophyseal diabetes insipidus. EMBO J 11: 19, 1992.

12) Yuasa $H$, Ito $M$, Nagasaki $H$, et al. Glu-47, which forms a salt bridge between neurophysin-II and arginine vasopressin, is deleted in patients with familial central diabetes insipidus. J Clin Endocrinol Metab 77: 600, 1993.

13) Repaske DR, Browning JE. A de novo mutation in the coding sequence for neurophysin II $\left(\mathrm{Pro}^{24} \rightarrow\right.$ Leu $)$ is associated with onset and transmission of autosomal dominant neurohypophyseal diabetes insipidus. J Clin Endocrinol Metab 79: 421, 1994.

14) Nagasaki $H$, Ito $M$, Yuasa $H$, et al. Two novel mutations in the coding region for neurophysin-II associated with familial central diabetes insipidus. J Clin Endocrinol Metab 80: 1352, 1995.

15) Rauch F, Lenzner C, Nurnberg P, Frommel C, Vetter U. A novel mutation in the coding region of neurophysin-II is associated with autosomal dominant neurohypophyseal diabetes insipidus. Clin Endocrinol (Oxf) 44: 45, 1996.

16) Hansen LK, Rittig S, Robertson GL. Genetic basis of familial neurohypophyseal diabetes insipidus. Trends Endocrinol Metab 8: 363, 1997.

17) Repaske DR, Phillips III JA. The molecular biology of human hereditary central diabetes insipidus. Prog Brain Res 93: 295, 1992.

18) Ito $\mathrm{M}$, Jameson JL, Ito $\mathrm{M}$. Molecular basis of autosomal dominant neurohypophyseal diabetes insipidus: cellular toxicity caused by the accumulation of mutant vasopressin precursors within the endoplasmic reticulum. J Clin Invest 99: 1897, 1997. 